\title{
A VOZ MÉDIA COMO ESTRATÉGIA DE ISENÇÃO DE RESPONSABILIDADE
}

\section{THE MIDDLE VOICE AS A STRATEGY TO AVOID RESPONSIBILITY}

\author{
Maria Claudete Lima ${ }^{1}$ \\ Universidade Federal do Ceará (UFC) \\ Universidade Presbiteriana Mackenzie (UPM)
}

\begin{abstract}
RESUMO
Numa perspectiva funcional, a gramática é considerada a codificação de valores semânticos e pragmáticos em que entram em jogo, entre outros fatores, a intenção comunicativa do falante (GIVÓN, 1993). A categoria de voz, relacionada à escolha do sujeito, configura-se como uma estratégia discursiva para focalizar ou desfocalizar determinado participante. Na voz média, em especial, o sujeito é o paciente do processo e o agente é totalmente desfocalizado. O objetivo deste artigo é analisar, em dados do português oral espontâneo a voz média como estratégia de isenção de responsabilidade. Para tanto, examina, quali-quantitativamente, 355 ocorrências de voz média, retiradas do corpus C-Oral Brasil, investigando entre outros fatores, se o desencadeador do processo, embora não presente na oração medial, se encontra no contexto ou pode ser identificado. Os resultados apontam que, na voz média, o desencadeador do processo raramente é codificado e, quando presente no contexto, é predominantemente abstrato ou interno. Tais dados, associados à tendência de afetação negativa com verbos de eventos espontâneos (ou tidos como tais) e verbos de emoção, favorecem seu emprego como estratégia de isenção de responsabilidade.
\end{abstract}

PALAVRAS-CHAVE: voz média; impessoalidade; gramática funcional; demoção do agente.

\begin{abstract}
From a functional perspective, grammar is the codification of semantic and pragmatic values in which the speaker's communicative intention comes into play (GIVÓN, 1993). The voice category is a discursive strategy to focus or defocus a particular participant. In the middle voice, the agent is totally out of focus. The purpose of this article is to analyze the middle voice as a strategy to avoid responsibility by defocusing the agent. Therefore, based on a quali-quantitative analysis of a spontaneous speech Brazilian Portuguese corpus, it investigates, in 355 occurrences of middle voice, whether the trigger of the process, although not present in the medial clause, is present in the context or can be identified. The results show that, in the middle voice, the trigger of the process, when present in the context, is predominantly abstract or internal, which allows its use as a strategy to avoid responsibility. The results show that, in the middle voice, the trigger of the process is rarely coded and, when present in the context, it is predominantly abstract or internal. These findings, associated with a tendency of negative affectation in verbs of spontaneous events (or taken as such) and emotional verbs, support the conclusion that middle voice is used as a strategy to avoid responsibility.
\end{abstract}

KEYWORDS: middle voice; impersonality; functional grammar; agent demotion.

\section{INTRODUÇÃO}

$\mathrm{Na}$ tradição gramatical, as construções de vOz são estudadas como meras alternativas formais. A passiva, por exemplo, é considerada em sua relação com a ativa, enfatizando-se

\footnotetext{
${ }^{1}$ Pós-Doutoranda da Universidade Presbiteriana Mackenzie (UPM). Professora Associada da Universidade Federal do Ceará (UFC) e do Programa de Pós-Graduação em Estudos da Linguagem (UFRN). E-mail: claudete@ufc.br
} 
simplesmente a conversão de uma na outra, como se fossem sinônimas (SENNA, 2014). Já muitos estudos, em especial, os pautados em abordagens funcionalistas, mostraram o papel discursivo desempenhado pelas construções de voz tanto em português (FURTADO DA CUNHA, 1994; 2000; CAMACHO, 2003, 2006; HAWAD, 2004; MELO, 2015), como em outras línguas (KANTA, 2015; MALICKA-KLEPARSKA, 2016; LEKAKOU; PITTEROFF, 2018).

Furtado da Cunha (1994) argumenta em favor do papel discursivo da passiva participial em português na organização textual. Hawad (2004) estuda a passiva analítica e a chamada passiva sintética em português e mostra, com base na Linguística Sistêmico-Funcional, que se diferenciam semântica e discursivamente quanto ao fluxo informacional. A passiva analítica tem como principal função manter o tópico discursivo, já a passiva sintática dá proeminência ao processo. Também numa abordagem funcional, mas na perspectiva de Givón, Kanta (2015) estuda a passiva no francês escrito e conclui que há cinco formas de passiva que vão da mais prototípica — formada por être + particípio passado (que corresponde à passiva com ser e particípio passado em português) — às menos prototípicas: a passiva sem o auxiliar être, apenas com particípio e sentido passivo; a passiva com clítico se e a passiva com o sujeito on que serve para demover o agente. Camacho (2006) mostra que há uma gradação nas construções de voz em português, em que a passiva e a impessoal estão nos extremos do contínuo, e a média e a reflexiva ficam no meio da escala, compartilhando traços ora com a passiva, ora com a impessoal. Para isso, o autor considera dois aspectos: a relativa topicalidade do agente e do paciente, e o grau de distintividade dos participantes, tal como proposto por Kemmer (1994). Igualmente apoiada em Kemmer (1993), Malicka-Kleparska (2016) defende que, no antigo eslavo eclesiástico, a oposição no sistema de voz não era entre ativa e passiva, mas entre ativa e média. A autora observa que muitas das classes semânticas propostas por Kemmer (1993) se manifestam no eslavo eclesiástico antigo. Baseada na Linguística Funcional Centrada no Uso, Melo (2015) estuda a voz média em textos de reclamação em português e conclui que a construção enfatiza o argumento afetado e ignora o agente ou o causativo, por ser irrelevante na situação comunicativa. Lekakou e Pitteroff (2018) focam a voz média disposicional impessoal em alemão e holandês, ou seja, uma construção medial impessoal, como em alemão Es siţ̨t sich angenehm auf diesem Stubl (senta-se confortavelmente nesta cadeira). Os autores argumentam que, nesse tipo de vOZ média, a noção de disposição é atribuída à própria eventualidade e não ao paciente ou tema.

Como se vê, nessa breve revisão de literatura, a maioria dos estudos sobre voz focaliza a passiva. Embora a voz média - entendida como uma construção de voz não agentiva, com sujeito afetado - tenha sido relativamente explorada em outras línguas, sua descrição e seu emprego em português só recentemente vêm sendo estudados. Ainda assim, com raras exceções, grande parte das pesquisas limita-se a explorar o emprego do clítico medial em abordagem variacionista (SAKAMOTO, 2008; BRITO, 2013) ou a propor uma descrição formal (WHITAKER FRANCHI, 1989; PACHECO, 2008; RAPOSO, 2013). O objetivo deste trabalho é analisar a voz média em português, numa perspectiva funcional, como estratégia para evitar responsabilidade. Essa função relaciona-se a uma propriedade semântico-discursiva geral ligada à ideia de impessoalidade, como discutida em Givón (1982). Sobre ela, estudou Lima (2014), que analisou, em corpus escrito do português medieval, as construções médias, passivas e impessoais. A autora chegou à conclusão de que a voz média é menos causal que as demais construções analisadas e que é predominantemente empregada para codificar eventos espontâneos ou tidos como tais, como já propunha Said Ali (1964).

Esta pesquisa tem objetivo mais restrito que a de Lima (2014), porque tomará como foco apenas a voz média como recurso para evitar assumir responsabilidade. Além disso, investiga o tema em corpus oral do português contemporâneo com o fim de contribuir para a descrição do uso da voz média em português atual, em situações de interações espontâneas, contextos favoráveis ao emprego de estratégias de evitação de responsabilidade.

O artigo acha-se dividido em cinco seções, após essas considerações iniciais: apresenta-se o tratamento da categoria de voz na abordagem givoniana da gramática. Em seguida, trata-se exclusivamente da vOz média em português. Na quarta seção, traça-se brevemente o percurso 
metodológico da pesquisa, para na seção seguinte, discutirem-se os principais achados. Por fim, pontuam-se as conclusões do estudo nas considerações finais.

\section{A voz na gramática funcional}

Para Givón (1995), a voz é um dos mais complexos domínios funcionais da linguagem, por, funcionalmente, cobrir uma larga extensão de dimensões semânticas e pragmáticas, que interagem de forma complexa, e por, estruturalmente, ser codificada em qualquer língua natural por uma extensa família de construções gramaticais distintas. Assim considerada, a voz é estudada sob duas dimensões funcionais: a semântica e a pragmática. A dimensão semântica se relaciona aos três aspectos que definem um evento transitivo prototípico, quais sejam: o agente é volitivo e ativo, ou seja, é a causa saliente do evento; o paciente é concreto e registra os efeitos da ação do agente; e o verbo codifica uma ação limitada e real. Já a dimensão pragmática da voz relaciona-se à topicalidade ${ }^{2}$ relativa do agente e do paciente num evento transitivo.

Com base nessas duas dimensões, Givón $(1993,1995)$ distingue a voz ativa das vozes detransitivas, que envolvem um decréscimo de uma ou mais de uma das propriedades transitivas: passiva, reflexiva, recíproca, impessoal e média, e define cada uma conforme o papel do sujeito e o grau de topicalidade. Voz ativa, por exemplo, é definida como aquela em que o agente é o tópico primário e sujeito da oração; e voz passiva como a oração em que o paciente é mais tópico que o agente, que é frequentemente demovido. Cada uma das construções de-transitivas se distingue uma da outra pelo grau de decréscimo nas propriedades da transitividade do qual decorrem as três principais funções do fenômeno de de-transitivização, segundo o autor:

1. demoção do agente: a demoção do agente pode atender a diferentes motivações. $\mathrm{O}$ agente pode ser desconhecido, pode ser predito anafórica ou cataforicamente, pode ser universal ou estereotipado e, ainda, pode simplesmente ser demovido como estratégia para evitar assumir responsabilidade.

2. promoção de um não-agente: consiste em, havendo a demoção do agente, outro participante ser interpretado como tópico. Nem toda construção detransitiva tem essa função. A impessoal, por exemplo, é não-promocional, uma vez que, embora demova o agente, o objeto se conserva como tópico secundário. Já a passiva e a média são promocionais.

3. estativização do verbo: nas construções de-transitivas um evento passa a ser codificado como estado resultante. Também não está presente em todas construções, mas se relaciona às construções promocionais (que envolvem a função (2)).

Este artigo estudará a função 1, que Givón (1982) inclui como um dos três domínios da voz: a impessoalização. Em português, as vozes de-transitivas são marcadas por uma perífrase, como a da passiva ser + v_do, ou por um clítico, que se manifesta na voz reflexiva, recíproca, média e impessoal clítica. Na seção a seguir, detalha-se a voz média, tema deste trabalho.

\section{A voz média em português}

$\mathrm{Na}$ tradicional descrição linguística do português, em geral, a voz média não recebe tratamento específico, dividindo com a reflexiva parco espaço, como sucede em Camara Jr (1977), para quem a voz medial, subdividida em reflexiva, dinâmica e expletiva, é definida como aquela em

\footnotetext{
${ }^{2}$ Givón (1993) considera tópico "aquilo de que se fala” e admite que um referente pode ser mais ou menos tópico a depender da importância temática (quantas vezes o referente é mencionado no contexto posterior) e da acessibilidade referencial (se é ou não encontrado nas três orações anteriores à ocorrência).
} 
que à forma ativa adjunge-se um pronome adverbal átono referente à pessoa do sujeito, indicando integração do sujeito na ação que dele parte.

Constitui exceção a esse tratamento conjugado, a descrição de Macambira (1986), que dedica algumas páginas à voz. média, distinta da reflexiva e da recíproca no quadro de vozes apresentado pelo autor. Nesse, a média, embora comungue com a reflexiva e a recíproca um mesmo esquema estrutural no que diz respeito aos elementos obrigatórios, distingue-se destas pelos elementos opcionais. Assim, para o autor, as três vozes apresentam o seguinte esquema estrutural, em que A é o sujeito; $\mathrm{B}$, o pronome correferencial ao sujeito e $\mathrm{C}$, o verbo principal, todos obrigatórios como indica o sinal + antes das letras:

$$
+\mathrm{A}+\mathrm{B}+\mathrm{C}
$$

A distinção entre elas é feita por elementos opcionais (afora observações de caráter semântico, como o fato de, na reflexiva, o agente e o paciente serem a mesma personagem e, na recíproca, personagens distintos), a saber: a possibilidade de acréscimo de expressões como a mim mesmo, a si mesmo, a ti mesmo etc., na reflexiva, e um ao outro ou uns aos outros, na recíproca. A média seria caracterizada justamente por rejeitar ambos os acréscimos. Sobre ela, afirma o autor:

há uma certa relação de agente e paciente entre o sujeito e o conteúdo semântico do verbo. Quer dizer que o sujeito não é propriamente o agente do processo, mas atua como tal de certa maneira; não é propriamente paciente, mas sofre de certa maneira o efeito do processo verbal. Em suma, significa que o sujeito está apenas envolvido no processo. (MACAMBIRA, 1986, p.46).

Macambira (1986) comenta que, em meu amigo zangou-se com o vizinho, o sujeito entra como agente, não, porém, ao ponto de zangar-se a si mesmo, pois "vizinho" tem sua participação no processo. Não se trata de "meu amigo zangou meu amigo", "apenas indica envolvimento no processo" (MACAMBIRA, 1986, p. 46). Noutras palavras, o autor parece reconhecer a baixa distinguibilidade entre os participantes Iniciador e ponto de chegada na voz média, como propõe Kemmer (1993).

Diante da semelhança estrutural das vozes reflexiva, recíproca e média, Macambira admite que, muitas vezes, só o contexto discursivo pode esclarecer o tipo de voz, como se depreende a partir dos exemplos (1)-(3).

(1) Os meninos se feriram propositadamente (reflexiva)

(2) Os meninos se feriram na briga (recíproca)

(3) Os meninos se feriram na cerca (média)

Essa dependência contextual para distinguir reflexivas, recíprocas e médias em português aponta para a necessidade de um tratamento funcional da voz média. No âmbito do funcionalismo, como se discutiu na seção anterior, a média é estudada como um tipo de voz de-transitiva (GIVÓN, 1993), em que o paciente é tópico e "não há nenhum agente claramente responsável pelo evento e nenhuma ação" (GIVÓN, 1993, p.75)³. Também Camacho (2002) observa:

a maioria dos casos de $\mathrm{vOz}$ média manifesta predicados com argumento único processado e todo o evento é tomado como não sendo o resultado da ação de uma outra entidade causativa. $\mathrm{O}$ sujeito parece ter alguma qualidade própria para gerar o processo que então só dele emana (CAMACHO, 2002, p.296).

Enfim, como mostra Kemmer (1993) em seu estudo cognitivo-tipológico: a voz média é uma categoria semântica coerente e complexa que recebe instanciação gramatical em muitas línguas, caracterizada pelo baixo grau de elaboração de eventos, ou seja, pelo grau com que facetas de uma situação particular, isto é, os participantes e os subeventos concebíveis na situação, são

\footnotetext{
3 There is no clearly discernible responsible agent, and thus no action (GIVÓN, 1993, p.75).
} 
distintos. Reflete, assim, conceitualizações alternativas do falante, que tem a escolha de fazer referência a eventos como um todo indiferenciado, ou referir-se a subestruturas ou partes componentes deste evento. Nas palavras de Kemmer (1993):

léxico e gramática podem ser pensados como análogos a um microscópio que permite ao usuário selecionar diferentes níveis de resolução para os vários objetos físicos observados. Ao escolher um meio de expressão particular (limitado, claro, pelos padrões de expressão convencionais), o falante pode efetivamente aumentar ou diminuir a resolução de um dado evento, de modo a salientar sua estrutura interna em maior ou menor medida, conforme suas necessidades expressivas numa dada situação (KEMMER, 1993, p. 210) $)^{4}$.

Para a autora, a intransitividade morfossintática da média é simplesmente uma manifestação formal de uma estrutura de evento menos elaborada. Devido à baixa distinguibilidade dos participantes, as construções que expressam eventos médios tomam as propriedades da intransitividade superficial que se relaciona prototipicamente a eventos de um participante. A morfologia média pode ser vista, portanto, como uma estratégia de variação na estrutura conceitual de eventos. Sua função mais específica é assinalar um afastamento do evento transitivo canônico na direção do evento intransitivo.

Partindo desta visão, Kemmer (1993) propõe classes de eventos que costumam estar relacionados à vOz média em várias línguas: ações de cuidados corporais (barbear-se, pentear-se etc.), mudança de postura (sentar-se, levantar-se, etc.), movimentos translacionais (deslocar-se, afastar-se etc.), movimentos não-translacionais (virar-se, posicionar-se etc.), eventos emocionais (zangar-se, alegrar-se etc.), eventos espontâneos (ferir-se, afundar-se), eventos mentais (esquecer-se, lembrar-se etc.), eventos naturalmente reciprocos (casar-se), atos de fala emotivos (queixar-se), média indireta (apossar-se).

$\mathrm{Na}$ perspectiva funcional, a voz média em português compreende construções que possuem em comum as seguintes propriedades propostas por Givón (1993) para a média em inglês:

(i) a função de demoção do agente/causativo. Em nenhuma dessas formas, diferentemente da passiva participial, o agente poderá ser recuperado. Observe-se a propósito a agramaticabilidade de (4). Essa impossibilidade de recuperação é o que dá à média o valor de impessoalidade que lhe permite ser empregada como estratégia de isenção de responsabilidade.

(4) a. o nosso carregador estragou (BFAMCV31)

b. ${ }^{*}$ o nosso carregador estragou pelos alunos.

(ii) a relação com uma correspondente ativa que expressa o mesmo conteúdo proposicional com o agente expresso:

(5) a. o carregador estragou (BFAMCV31)

b. o aluno estragou o carregador.

(iii) a transitividade verbal. $\mathrm{O}$ verbo é inerentemente transitivo, ou seja, um verbo com dois argumentos (verbos de ação-processo) que passou a ter um só — argumento paciente ou experienciador - com a demoção do agente/causativo. A demoção pode ser total, quando o agente/causativo não é expresso na oração (6), ou parcial, quando se manifesta na forma de um sintagma preposicionado (7).

\footnotetext{
${ }^{4}$ Lexicon and grammar can be thought of as analogous to a microscope which allows the user to select different levels of resolutions for the various physical objects observed. In choosing a particular linguistic means of expression (constrained, of course, by conventional patters of expression), the speaker can effectively turn up or turn down the resolution on given event so as to highlight its internal structure to a greater or lesser extent, according to his or her expressive needs in a given situation. (KEMMER, 1993, p.210)
} 
(6) o barco que virou no réveillon / de / oitenta-e-oito // (BFAMMN36)

(7) enquanto cê distrai com esse modelo aqui (BPUBDL02)

(d) a promoção do objeto a tópico primário, como em (8)

(8) *ONO: que o porco baixou demais / direto // (BFAMCV10)

Considera-se, assim, que em português, há duas formas de codificação da voz média: (a) média não-clítica; (b) média intransitiva clítica. Como a média não permite a menção de um agente, a voz média é uma construção por excelência para codificar eventos espontâneos ou apresentados como tais pelo falante como estratégia para evitar assumir responsabilidade. A ser assim, pressupõese que a média deverá codificar essencialmente eventos de afetação negativa, o que se testará neste trabalho. pesquisa.

$\mathrm{Na}$ seção a seguir apresenta-se com mais vagar os procedimentos metodológicos desta

\section{Metodologia}

Este trabalho faz uma análise quanti-qualitativa de ocorrências de voz média coletadas no banco de dados C-ORAL BRASIL I, corpus do português oral espontâneo (RASO; MELLO, 2012), com 208.130 palavras em 21:08:52 horas de gravação, distribuídas nos contextos familiar e público, em três situações comunicativas: diálogo (dois participantes), conversação (mais de dois participantes) e monólogo (um participante). As ocorrências estão identificadas conforme o inquérito de onde foram retiradas: $\mathrm{B}=\mathrm{Brasil} ; \mathrm{FAM}=$ familiar; $\mathrm{PUB}=$ público; $\mathrm{CV}=$ conversação; $\mathrm{DL}=$ diálogo e $\mathrm{MN}=$ monólogo. Cada inquérito é codificado com 4 índices: BFAMCV02, por exemplo, indica uma ocorrência do corpus do contexto familiar, conversação, inquérito $n^{\circ} 02$. Para fins de comparação, serve-se eventualmente de ocorrências da Web e do Corpus do Português, aba Now. Nesses casos, as ocorrências são identificadas pelo nome do site, seguida da URL em rodapé.

As ocorrências de vOz média coletadas desse banco de dados foram categorizadas quanto aos seguintes fatores: (a) tipo de codificação: pronominal e não-pronominal; (b) grau de animacidade do sujeito: animado humano, animado animal, inanimado concreto, inanimado abstrato. (c) codificação do causativo/agente: codificado, quando o desencadeador do evento figura no contexto próximo ou remoto; inferível, quando, mesmo não codificado no contexto, seja possível inferir do contexto; não-identificável, quando não é possível discernir um agente ou causativo responsável pelo evento; (d) saliência do causativo: postulada em termos do grau de animacidade ou empatia (LANGACKER, 1991) e da visibilidade: externo animado humano, externo animado animal, externo inanimado concreto, externo inanimado abstrato, interno abstrato, inconcebível. Com base nesses traços conjugados ao fator (c), os causativos foram classificados em três graus de saliência: alta (animado + codificado/inferível humano), média (codificado/inferível concreto), baixa (codificado/inferível/abstrato interno e externo e não-identificável) e nula (nãoidentificável/inconcebível), quando não há causativo discernível; (e) tipo de afetação do SN sujeito: positiva, negativa, neutra. A afetação é positiva ou negativa, conforme efeito provocado pela mudança seja considerado axiologicamente, respectivamente, positivo ou negativo. Exemplo claro de afetação positiva seria alegrar-se e de afetação negativa, zangar-se. A afetação é neutra quando, mesmo ocorrendo mudança, esta não traz efeitos negativos nem positivos, como lembrar-se, acostumar-se.

Após a categorização, os dados foram tratados estatisticamente no programa PSPP, versão 1.2.0, que nos deu as frequências e o cruzamento das variáveis. 


\section{Resultados e discussão}

Foram coletadas 355 ocorrências de voz média clítica e não-clítica. O causativo apresentase no contexto prévio ou na própria oração em $23 \%$ das ocorrências $(83 / 355)$, como ilustram as frases (9-11).

(9) *ECR: chegou lá / e' \&nin [/1] encantou com as codorna / (BFAMDL15)

(10) *ASI: <Nossa / encheu a vasilha $>$ aqui de arroz // sobrou bastante // (BFAMDL16)

(11) eu acho que a fé era muita também / <melhorava > na hora / né // (BFAMMN14)

Em (9), o causativo é codorna e em (10), arroz̧ ambos são codificados como sintagma preposicionado na própria oração: As codornas o encantaram, $O$ arroz encheu a vasilha. Em (11), o causativo não está codificado na própria oração média, mas no contexto prévio que deixa implícita a atribuição de responsabilidade do evento seguinte: "a fé, que era muita, fazia melhorar [a saúde]".

Esse tipo de relação causal é bem comum no corpus. Todavia, mais comum é a omissão do causativo não só na oração média, mas também no contexto. Em $77 \%$ das ocorrências, o causativo não está presente no contexto. Desse total, o causativo é inferível em 32,7\% (116/355), como nas frases (12-14).

(12) *SIL: oprano de saúde ia aumentar [/2]=SCA= vai aumentar de novo (BFAMDL04)

(13) *ATA: fratura exposta / cê operou / né // (BFAMCV13)

(14) < agora eu tenho que ter mais juízo / pa comer> pra não engordar muito> porque engorda / né // < depois que volta / engorda tudo de novo > // (BFAMCV06)

Em (12), embora não esteja explícito, infere-se, pelo contexto, que o causativo é um humano (ou instituição humana) responsável pelo aumento de preço dos planos de saúde: o governo, os órgãos regulares dos planos de saúde. Também em (13), infere-se um agente: o cirurgião. Em (14), o contexto e o conhecimento de mundo permitem inferir que o causativo é comida.

O causativo é não-identificável em 44\% (156/355), como se vê em (15), em que o contexto não permite identificar nenhuma causa discernível. Nesse caso, o evento costuma ser dado como espontâneo, ocorrendo de modo natural, geralmente, devido a alguma propriedade interna do afetado; no caso ilustrado, a propriedade de cristalizar. Em (16), essa propriedade é explicitada na oração posterior: a causa do evento é atribuída à propriedade do objeto: ser ruim. Em (17), também a causa é codificada na oração posterior, mas o evento "a tatuagem empolar" é atribuído a uma propriedade do humano que possui a tatuagem, não exatamente da tatuagem em si.

(15) *CAR: <é> // isso aí é o que / Getúlio // \&he / embaixo / aí / era cera / *GET: \&he / não é [/1] é / <que> cristalizon / né // (BPUBDL05)

(16) essas a [/1] vão derretendo / né // é meio ruim // (BFAMCV26)

(17) *ANC: empolou / uai // porque ela também tem alergia // (BFAMCV20)

Trata-se de conceber o evento como derivado da substância da coisa afetada, como dizia Aristóteles a respeito da espontaneidade. Segundo Abbagnano (2000, p. 357), para o filósofo "uma ação é espontânea quando seu princípio está no agente".

Algumas vezes a mudança é atribuída a um evento anterior, numa cadeia de ação, como em (18-20).

(18) eu comecei pedir a Nossa Senhora / e as coisas ficou boa // foi melhorando / foi melhorando os pouco (BFAMMN26)

(19) *HER: vai lá na lavanderia e desliga a máquina pra mim / que senão vai / o sabão <vai $>$ $<$ perder todo $>$ // (BFAMMN18) 
(20) e aí ele cansa / na maioria das vezes dá câimbra / e aí desespera / e quando desespera comę̧a a afogar // < normalmente é> sempre assim // (BFAMMN36)

Em (18), o primeiro evento "pedir a Nossa Senhora" desencadeia "as coisas ficaram boas" e "foi melhorando aos poucos". Em (19), há dois eventos sequenciados necessários para evitar o evento de mudança "o sabão perder-se": "ir à lavanderia" e "desligar a máquina”. No exemplo (20), a cadeia de ação é ainda mais evidente com a repetição da conjunção. Cada efeito de um evento anterior torna-se causa do evento seguinte, numa clara cadeia causal, representada como em (21):

(21) Cadeia causal: ele cansa > ele se desespera $>$ ele começa a afogar

Com base na escala de empatia, que vai do animado humano ao inanimado abstrato, considera-se que há menor probabilidade de entidades abstratas serem escolhidas como sujeito. Embora a voz média não pareça ter como função primordial a perspectivação do estado de coisas, como tem a voz passiva, o causativo da média é predominantemente abstrato: 48,4\% (172/355), o que mostra a baixa probabilidade de ser escolhido como sujeito numa oração ativa. Apenas $20 \%$ são causativos animados e $26,5 \%$ não permitem identificar sequer a natureza, se abstratos ou concretos. A tabela 1 apresenta o cruzamento da variável codificação e grau de animacidade.

Tabela 1: Codificação do causativo $x$ grau de animacidade

\begin{tabular}{|c|c|c|c|c|c|c|c|c|}
\hline \multicolumn{9}{|c|}{ Codificação do causativo } \\
\hline \multirow[t]{2}{*}{ Escala de empatia } & \multicolumn{2}{|c|}{ codificado } & \multicolumn{2}{|c|}{ Inferível } & \multicolumn{2}{|c|}{ Não identificável } & \multicolumn{2}{|c|}{ Total } \\
\hline & $\mathrm{N}^{\mathrm{o}}$ & $\%$ & $\mathrm{~N}^{\mathrm{o}}$ & $\%$ & $\mathrm{~N}^{\mathrm{o}}$ & $\%$ & $\mathrm{~N}^{\mathrm{o}}$ & $\%$ \\
\hline humano & 1 & $1,4 \%$ & 70 & $98,6 \%$ & 0 & $0 \%$ & 71 & $20 \%$ \\
\hline animal & 2 & $100 \%$ & 0 & $0 \%$ & 0 & $0 \%$ & 2 & $0,6 \%$ \\
\hline Inanimado concreto & 6 & $37,5 \%$ & 10 & $62,5 \%$ & 0 & $0 \%$ & 16 & $4,5 \%$ \\
\hline Inanimado abstrato & 74 & $43 \%$ & 36 & $21 \%$ & 62 & $36 \%$ & 17 & $48,4 \%$ \\
\hline inconcebível & 0 & $0 \%$ & 0 & $0 \%$ & 94 & $0 \%$ & 94 & $26,5 \%$ \\
\hline Total & 83 & $23,4 \%$ & 116 & $32,7 \%$ & 156 & $44 \%$ & $\begin{array}{l}35 \\
5\end{array}$ & $100 \%$ \\
\hline
\end{tabular}

Fonte: elaborada pelo autor

Os causativos humanos na voz média, além de pouco frequentes, são predominantemente inferíveis. Ocorrem com verbos como casar(-se), operar(-se), capacitar-se, entre outros, que pressupõem uma entidade ou instituição humana como Causativo ${ }^{5}$ :

(22) a. LIA: e' tirou os ponto / n? vai operar mais nada / né // (BFAMDL25)

b. Nesta quarta-feira, o paciente deu entrada no bloco cirúrgico, mas o médico operou a perna errada (Clube Notícia) ${ }^{6}$

(23) a. eu casei / com ele // ele é meu marido (BFAMDL23)

b. Padre que casou dois homens diz que pensava ter casado marido e mulher (Cada Minuto $)^{7}$

(24) a. foi / criado nos Estados Unidos / formou em medicina (BFAMCV20)

\footnotetext{
${ }^{5}$ Nestas sequências de exemplos, apresentam-se ocorrências de orações ativas retiradas da Web para comparar com a construção média encontrada no corpus.

${ }^{6}$ https://www.clubenoticia.com.br/Noticia/index/1539/Medico_opera_perna_errada_de_paciente_no_Hospital_R egional

7 https:/ / www.cadaminuto.com.br/noticia/41927/2009/12/06/padre-que-casou-dois-homens-diz-que-pensava-tercasado-marido-e-mulher
} 
b. Em solenidade histórica, Ufersa forma maior número de concluintes em 2016.1 (UFERSA) ${ }^{8}$

c. O pró-reitor de Extensão e Cultura, Daniel Prado, representando a reitora da FURG, formou a primeira turma de alunos do curso de Agroecologia Bacharelado (FURG) ${ }^{9}$

$\mathrm{Na}$ voz média, há predominância de causativos abstratos e inconcebíveis, que têm baixa saliência, o que se manifesta linguisticamente com sua não-codificação. Do total de causativos codificados, predominam os abstratos, o que pode se relacionar à função de isenção de responsabilidade. Em (25), por exemplo, deduz-se que é por estarem podres que os retalhos de tecido se dissolvem. Em (26) a responsabilidade do evento de mudança é atribuída explicitamente à propriedade de o arroz ser novo, e não a alguma ação ou ausência de ação do enunciador, o ter colocado muita água ou ter deixado muito tempo no fogo, por exemplo.

(25) *MAE: <então [/1] hhh então eu puxei assim / eles / hhh> // *PAI: <"levemente"> // < podre $>/ /<$ detonado $>/ / *$ MAE: pois é // aí <hhh $>/ * \mathrm{PAI}:<$ dissolvendo $>/ /$ (BFAMCV19)

(26) *FLA: [561] ele empapuça [/1] empapuça //... eh / quer dizer / a culpa é do arroz / né //...porque e' tá novo //...culpa é do arroz //

A atribuição de responsabilidade a uma entidade abstrata, exterior ou interior à entidade afetada, dependerá de a entidade abstrata ser tida como "apta a provocar a mudança" percebida. Por vezes, a mudança é atribuída à propriedade de uma outra pessoa que não o afetado. Nesse caso, a concepção do evento dissocia em duas entidades conceituais uma única entidade experiencial concreta. Contrastemos dois exemplos do Corpus do Português, aba Now (2012-2019), com morrer, um verbo media tantum:

(27) "Ela [a funcionária do posto de saúde] não deu essa carta. Minha filha morreu por causa da negligência dela", afirmou Adriano da Silva (G1 ${ }^{10}$

(28) Demi Lovato quase morreu por causa dos fãs nas ruas de São Paulo (Blasting News) ${ }^{11}$

Em (27), a dissociação em dois nomes da causa da morte da filha reduz a responsabilidade da funcionária sobre o evento. Isso se manifesta gramaticalmente pelo estatuto sintático de satélite do sintagma nominal (a negligência dela), tornando a causa mais indireta. Já na segunda frase, a responsabilidade das fãs é mais saliente, o que se manifesta na codificação de um único nome como núcleo do SN, encaixado no SP causal como no primeiro exemplo: os fãs. Noutras palavras, a causa é mais direta e saliente quando o desencadeador é uma entidade concreta, como em (28). Portanto, o falante pode reduzir a responsabilidade de uma entidade desencadeadora de um evento de modo a tornar a relação causal mais indireta até ao ponto de não a enunciar ou atribuí-la a uma entidade abstrata.

Se a voz média for empregada como recurso para evitar assumir responsabilidade, esperase que codifique, predominantemente, eventos que afetem o sujeito de forma negativa. O gráfico 1 mostra os resultados quanto a essa variável.

\footnotetext{
8 https://assecom.ufersa.edu.br/2016/12/19/em-solenidade-historica-ufersa-forma-maior-numero-de-concluintesem-2016-1/

9 https://www.furg.br/en/noticias/noticias-sls/formaturas-em-sao-lourenco-do-sul-sao-marcadas-por-estreias

10 https://g1.globo.com/ba/bahia/noticia/2019/03/20/funcionarios-de-dois-postos-acusam-familiares-de-gravidaque-perdeu-bebe-de-ameaca-na-ba-familia-nega-e-aponta-negligencia.ghtml

11 http:/ / br.blastingnews.com/tv-famosos/2015/10/loucura-demi-lovato-quase-morreu-por-causa-dos-fas-nasruas-de-sao-paulo-00622111.html
} 
Gráfico 1: tipo de afetação do sujeito da voz média

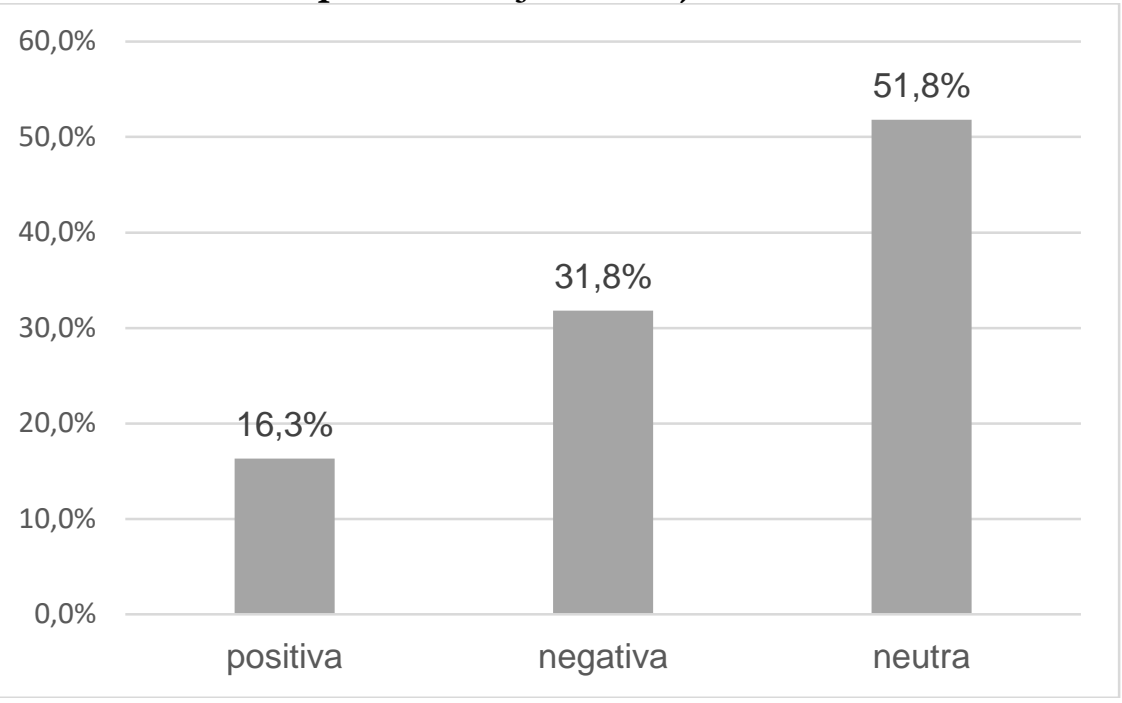

Fonte: elaborado pelo autor.

Observa-se que pouco mais da metade das ocorrências codifica afetação neutra (184/355), o que contraria a hipótese inicial. Nos dados, a afetação negativa é o segundo tipo mais frequente e a afetação positiva tem pouca representatividade no corpus: apenas 16,3\% (58/355).

Supondo-se que a predominância de afetação neutra poderia dever-se à alta frequência de alguns lemas, com valor axiológico neutro, como casar (14/128), lembrar (39/128), acostumar $(12 / 128)$, reduziram-se todas as ocorrências aos lemas e respectivos valores de afetação. Como alguns lemas (acabar, amadurecer, aumentar) foram empregados com mais de um valor de afetação, a depender do contexto, foram computados como novos lemas. A afetação neutra manteve-se predominante: 46,2\% (61/132). Há 35,6\% (47/132) de afetação negativa e 18,2\% (24/132) de afetação positiva.

Diante desses resultados, cabe observar o grau de animacidade do sujeito da voz média em relação com a variável afetação. Os resultados estão dispostos na tabela 2.

Tabela 2: Relação entre tipo de afetação e animacidade do sujeito

\begin{tabular}{|c|c|c|c|c|c|c|c|c|}
\hline \multicolumn{9}{|c|}{ Tipo de afetação } \\
\hline \multirow[t]{2}{*}{ Escala de empatia } & positiva & & \multicolumn{2}{|c|}{ Negativa } & \multicolumn{2}{|c|}{ neutra } & \multicolumn{2}{|c|}{ Total } \\
\hline & $\mathrm{N}^{\circ}$ & $\%$ & $\mathrm{~N}^{\mathrm{o}}$ & $\%$ & $\mathrm{~N}^{\mathrm{o}}$ & $\%$ & $\mathrm{~N}^{\mathrm{o}}$ & $\%$ \\
\hline Humano & 38 & $18,7 \%$ & 39 & $19,2 \%$ & 126 & $62 \%$ & 20 & $57,2 \%$ \\
\hline Animal & 2 & $182 \%$ & 5 & $45,4 \%$ & 4 & $36,4 \%$ & $\begin{array}{l}3 \\
11\end{array}$ & $3.1 \%$ \\
\hline Inanimado concreto & 12 & $9,7 \%$ & 62 & $50,4 \%$ & 49 & $39,8 \%$ & 12 & $34,6 \%$ \\
\hline Inanimado abstrato & 6 & $33,3 \%$ & 7 & $38,9 \%$ & 5 & $27,8 \%$ & $\begin{array}{l}3 \\
18\end{array}$ & $5 \%$ \\
\hline Total & 58 & $16,3 \%$ & 113 & $31,8 \%$ & 184 & $51,8 \%$ & $\begin{array}{l}35 \\
5\end{array}$ & $100 \%$ \\
\hline
\end{tabular}

Fonte: elaborada pelo autor.

O sujeito neutramente afetado ${ }^{12}$, segundo os dados, é predominantemente humano. Já a afetação negativa ocorre com maior frequência com sujeitos inanimados, especialmente os concretos. A relação é bicondicional, o que mostra uma relação de influência de uma variável sobre a outra. Dá-se tanto na direção da afetação para o grau de animacidade, quanto do grau de

\footnotetext{
12 Por "neutramente afetado", afirma-se que o evento de mudança (que provoca afetação) não tem valor axiológico marcadamente positivo ou negativo, daí valor neutro.
} 
animacidade para a afetação. Se há sujeito inanimado, a tendência é afetação negativa. Se há sujeito humano, a tendência é a afetação neutra. $\mathrm{Na}$ outra direção, a afetação negativa é mais frequente com sujeitos inanimados e a neutra, com sujeitos humanos, o que pode ser indício da atuação da escala da empatia: uma tendência a falar de eventos que afetem neutramente humanos e a falar de eventos que afetem negativamente entidades inanimadas, mais distantes na escala da empatia.

A afetação negativa predomina com verbos de eventos espontâneos: 62\% (70/113), e verbos de emoção: 20,4\% (23/113). Novamente, a influência é bidirecional: dos 138 casos de eventos espontâneos, 50,7\% (70/138) são eventos de afetação negativa, contra 33,3\% (46/138) de afetação neutra. Do total de eventos de afetação neutra, a maioria são eventos mentais: $32 \%$ (59/184). O gráfico 2 a seguir permite visualizar com clareza a relação de influência entre tipo de evento e afetação ${ }^{13}$.

\section{Gráfico 2: Relação entre afetação e tipo de evento}

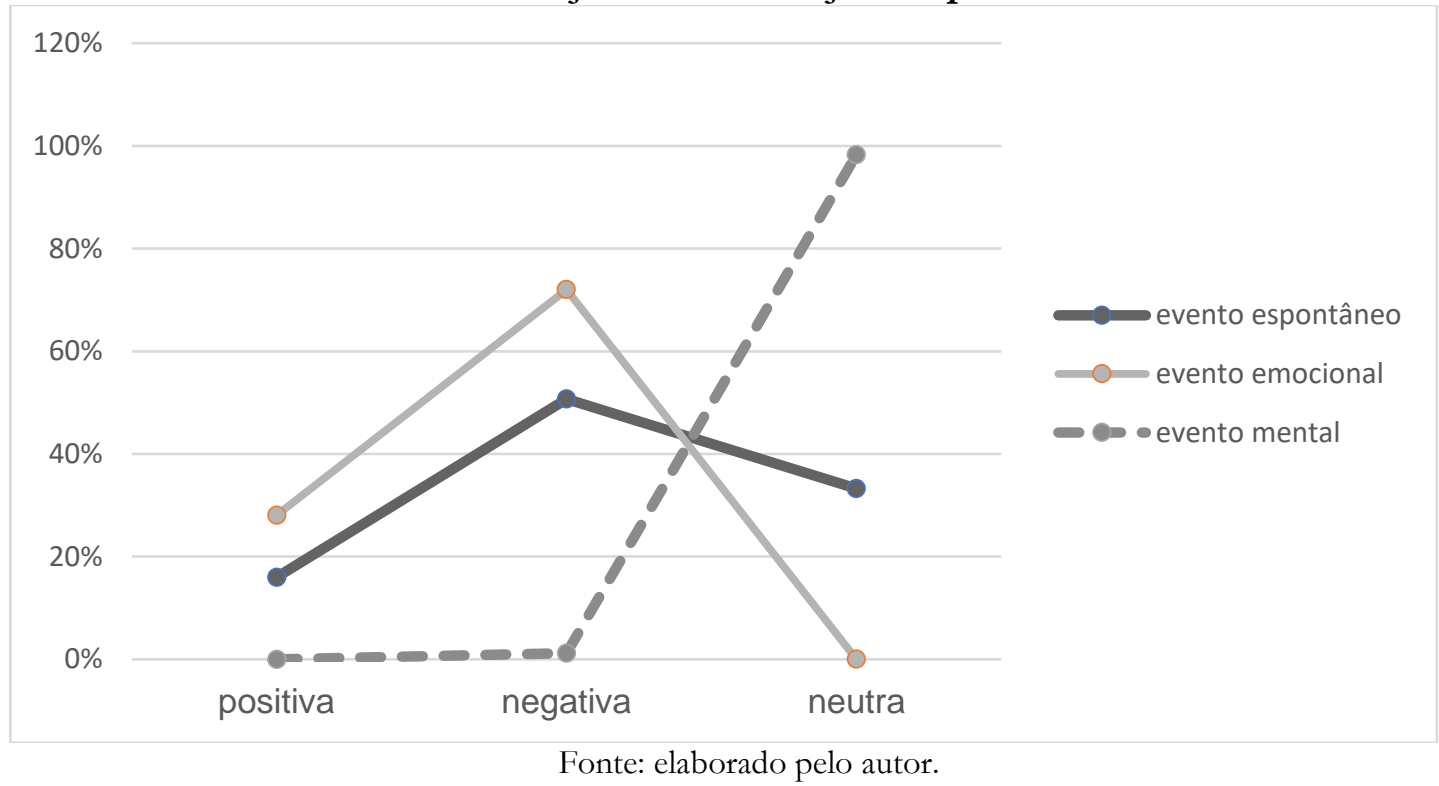

Há, portanto, um comportamento similar entre verbos de emoção e verbos de eventos espontâneos na codificação média, na tendência a representar eventos de afetação negativa. A sequência discursiva predominante no corpus, em todas as situações que abrange (diálogo, monólogo e conversa), é a narrativa. As pessoas falam de acontecimentos da sua vida e da vida dos outros. Nesse narrar, têm saliência os eventos negativos, tanto de mudança de estado físico (eventos espontâneos) como de mudança de estado emocional.

Essa tendência se coaduna ainda com a função da voz média de evitar responsabilidade. Ao escolher narrar um evento numa codificação média, sem codificar a causa, ou atribuindo o evento a uma entidade abstrata, o falante retira a responsabilidade do evento de si ou de terceiros. Um exemplo disso se depreende do diálogo a seguir, retirado do corpus.

(29) *MAR: ai bosta // ocê quebra meu $+<$ Nossa Senhora / cê quebrou minha $>$ [/1] meu $+$

*JOS: < quê> // < nem encostei> n' ocê / varão //

*MAR: Nosso Pai //

*CAR: ô varão / desculpa //

*MAR: < ai > //

*JOS: <tá valendo> / sô //

*MAR: volta // Nosso Pai //

${ }^{13}$ No gráfico, mostram-se apenas os resultados referentes aos eventos mais frequentes no corpus. 
*JOS: que que foi / ô //

*MAR: ai // quase quebrei meu dedo //

*JOS: eu nem encostei n' ocê não / uai //

$*$ CAR: <quatro a um / pra eles $>/ /$

$*$ CEL: Nossa / <nem eu aqui / Zé / o'> //

*MAR: < machucou aqui / Varão> / o' //

A situação comunicativa é um jogo de futebol entre os falantes. MAR se queixa de que JOS o machucou (ocê quebra meu $+<$ Nossa Senhora / cê quebrou minha $>[/ 1]$ meu + ). JOS nega $(<n e m$ encostei $>n^{\prime}$ ocê / varão //). MAR então não atribui a responsabilidade pelo machucado a nenhum deles, enuncia simplesmente o fato, usando uma oração média, com sujeito dêitico: Macbucou aqui $>$ Aqui [men dedo] machucou-se.

Feitas estas análises gerais, passa-se a resumir os principais achados na próxima seção.

\section{CONSIDERAÇÕES FINAIS}

O objetivo deste trabalho foi discutir a função discursiva da voz média de servir de estratégia para evitar atribuir responsabilidade. Após a análise de 355 ocorrências de voz média clítica e não-clítica no corpus C-Oral Brasil I, chegou-se às seguintes conclusões:

(a) Predominam orações médias sem causativo codificado nem mesmo no contexto prévio ou posterior: $77 \%$ (272/355); a maioria desses causativos é não-identificável: $44 \%$ $(156 / 355)$;

(b) Quando codificado ou inferível, o causativo da média é predominantemente abstrato: $48,4 \%(172 / 355)$

(c) Embora, no geral, predomine a afetação neutra (51,8\% - 184/355), há uma tendência à afetação negativa em três situações: com sujeitos inanimados; com verbos de eventos espontâneos e com verbos de emoção.

Tais resultados permitem caracterizar a voz média no português oral espontâneo como uma construção que codifica eventos espontâneos ou provocados por entidades abstratas, como outros eventos ou propriedades internas do próprio afetado. Uma vez que a codificação medial em si nem sempre permite distinguir se o desencadeador do evento teve ou não controle sobre o efeito, a construção serve para eximir uma dada entidade da responsabilidade sobre o evento expresso. Parece ser o caso do exemplo (29) comentado na seção anterior.

A propósito, cabe lembrar a pesquisa de Melo (2015). Embora o foco da autora não fosse avaliar essa função discursiva da média, a produtividade do fenômeno em textos de reclamação atestada pela autora revela a função discursiva da média investigada aqui. É possível, então, que alguns corpora, como o de Melo (2015), forneçam mais elementos para comprovar a função discursiva estudada neste artigo, o que poderá ser averiguado em outros trabalhos.

\section{REFERÊNCIAS}

ABBAGNANO, N. Dicionário de Filosofia. 4 ed. São Paulo: Martins Fontes, 2000.

BRITO, J. R. de S. Análise variacionista do clítico das estruturas de-transitivas mediais no português oral popular de Fortaleza. 2013. 152f. - Dissertação (Mestrado) - Universidade Federal do Ceará, Departamento de Letras Vernáculas, Programa de Pós-graduação em Linguística, Fortaleza, 2013. 
CAMACHO, R.G. Construções de voz. In: ABAURRE, M.B.; RODRIGUES, A. C. S. (Org.). Gramática do português falado. v. VIII: Novos estudos descritivos. Campinas, SP: Ed. da UNICAMP: FAPESP, 2002, p. 227-316.

CAMACHO, R. Em defesa da categoria de voz média no português. DELTA: Documentação e Estudos em Linguística Teórica e Aplicada. 19:1, pp. 91-122, 2003.

CAMACHO, Roberto Gomes. A gradação tipológica das construções de voz. Gragoatá, [S.l.], v. 11, n. 21, dec. 2006. ISSN 23584114. Disponível em: https://periodicos.uff.br/gragoata/article/view/33221. Acesso em: 06 sep. 2020.

CAMARA JR., J. M. Dicionário de linguística e gramática: referente à língua portuguesa. Petrópolis: Vozes, 1977.

FURTADO DA CUNHA, M. A. Motivações discursivas para o uso da passiva. DELTA: Documentação e Estudos em Linguística Teórica e Aplicada, [S.1.], v. 10, n. 1, out. 1994. ISSN 1678-460X. Disponível em: https://revistas.pucsp.br/delta/article/view/45462. Acesso em: 06 set. 2020 .

FURTADO DA CUNHA, M. A. A complexidade da passiva e as implicações pedagógicas de seu uso. Linguagem \& Ensino. Vol. 3, n.1, 2000, p. 107-116.

GIVÓN, T. Transitivity, topicality, and the ute impersonal passive. In HOPPER, Paul J.\& THOMPSON, Sandra A (ed) Syntax and semantics: studies in transitivity. Vol.15. New York: Academic Press, 1982.

GIVON, T. English grammar: a function-based introduction. Amsterdam: John Benjamins. v.1, 1993.

GIVÓN, T. Functionalism and grammar. Philadelphia, J. Benjamins, 1995.

HAWAD, H. F. A voz verbal e o fluxo informacional do texto. DELTA: Documentação e Estudos em Linguística Teórica e Aplicada. 20:1, 2004. pp.97-121.

KANTA, M. Analysis of passives constructions in French based on functional-typological grammar by Givón. Procedia - Social and Behavioral Sciences, 174, 2015. p. 313-320.

KEMMER, S. The middle voice. Amsterdam/Philadelphia: John Benjamins, 1993.

KEMMER, S. Middle voice, transitivity and the elaboration of events. In: FOX, B.; HOPPER, P.J. (Ed.). Voice: form and function. Amsterdam: John Benjamins, 1994, p. 179-230

LANGACKER, R. W. Foundations of cognitive grammar. Descriptive application. Stanford/California: Stanford University Press, 1991.

LEKAKOU, M., \& PITTEROFF, M. This is personal: Impersonal middles as disposition ascriptions. Glossa: A Journal of General Linguistics, 3(1), 2018, p. 59. DOI: http://doi.org/10.5334/gigl.487

LIMA, M. C. O continuum de não-atribuição de causalidade na Crônica Geral de Espanha de 1344. Filologia e Linguística Portuguesa, $[S$. l. $]$, v. 15, n. 1, p. 155-178, 2014. DOI: 
10.11606/issn.2176-9419.v15i1p155-178.

Disponível

em: https://www.revistas.usp.br/flp/article/view/76198. Acesso em: 17 jan. 2021.

MACAMBIRA, J. R. Estrutura do vernáculo. Fortaleza: EUFC, 1986.

MALICKA-KLEPARSKA, A. Old Church Slavonic as a language with the middle voice morphology. SKASE Journal of Theoretical Linguistics [online]. 2016, vol. 13, no.2. Disponível em: http://www.skase.sk/Volumes/JTL32/pdf doc/12.pdf.

MELO, N. M. S. C. de. A construção medial no português do Brasil: usos no padrão reclamação digital. 2015. 186 f. Tese (Doutorado em Estudos da Linguagem) - Programa de Pós-Graduação em Estudos da Linguagem, Universidade Federal do Rio Grande do Norte, Natal, 2015. Disponível em:

https://repositorio.ufrn.br/ispui/bitstream/123456789/20217/1/NadiaMariaSilveiraCostaDeMe lo TESE.pdf. Acesso em 30 ago. 2020.

PACHECO, J. da C. As construções médias do português do Brasil sob a perspectiva teórica da morfologia distribuída. 2008. 113 f. Dissertação (Mestrado em Linguística) - Programa de Pós-Graduação em Semiótica e Linguística Geral, Universidade de São Paulo, São Paulo, 2008

RASO, T., \& MELLO, H. (Eds.). C-oral-Brasil I: corpus de referência do português brasileiro falado informal. Belo Horizonte: Editora UFMG, 2012. Disponível em http://www.c-oralbrasil.org. Acesso em 10 jul. 2020.

RAPOSO, E. Verbo e sintagma verbal. In: Raposo, E. et al. (Orgs.). Gramática do Português (Vol II). Lisboa: Fundação Calouste Gulbenkian, 2013, cap. 28.

SAID ALI, M. Gramática histórica da língua portuguesa. São Paulo: Melhoramentos, 1964.

SAKAMOTO, C. T. A variação do se medial na fala de Florianópolis. 2008. 155 f. Dissertação (Mestrado em Linguística) - Curso de Pós-Graduação em Linguística, Universidade Federal de Santa Catarina, Florianópolis, 2008.

SENNA, L. A. Estruturas passivas e estratégias discursivas: sobre o currículo de língua portuguesa no Ensino Médio. Filologia e Linguística portuguesa, v. 15, n. 1, p. 269-303, 14 mar. 2014.

WHITAKER-FRANCHI, R. C.M. As construções ergativas. 1989. 190 f. Dissertação (Mestrado em Linguística). IEL/Universidade Estadual de Campinas, Campinas, 1989. 